\title{
TITLE:
}

\section{Can economic-psychological parameters predict successful smoking cessation?}

\section{$\operatorname{AUTHOR(S):~}$}

Ida, Takanori; Goto, Rei; Takahashi, Yuko; Nishimura, Shuzo

\section{CITATION:}

Ida, Takanori ...[et al]. Can economic-psychological parameters predict successful smoking cessation?. 京都大学大学院経済学研究科Working Paper 2008, 96

ISSUE DATE:

2008-08

URL:

http://hdl.handle.net/2433/65735

RIGHT: 
Working Paper

\title{
Can economic-psychological parameters predict successful smoking cessation?
}

\author{
Takanori Ida ${ }^{+}$ \\ Graduate School of Economics, Kyoto University, Kyoto 606-8501, Japan; ida@econ.kyoto-u.ac.jp

\section{Rei Goto} \\ Faculty of Economics, Konan University, Kobe 658-8501, Japan; reigoto@center.konan-u.ac.jp

\section{Yuko Takahashi} \\ Nara Women's University Health Service, Nara 630-8506, Japan; takahahi@cc.nara-wu.ac.jp

\section{Shuzo Nishimura} \\ Graduate School of Economics, Kyoto University, Kyoto 606-8501, Japan; shuzo@econ.kyoto-u.ac.jp
}

June 2008

${ }^{+}$Corresponding author: Takanori Ida, Graduate School of Economics, Kyoto University, Yoshida, Sakyo, Kyoto 606-8501, Japan; Tel. \& Fax: +81-75-753-3477; E-mail: ida@econ.kyoto-u.ac.jp 


\title{
Can economic-psychological parameters predict successful smoking cessation?
}

\author{
Takanori Ida ${ }^{+}$ \\ Graduate School of Economics, Kyoto University, Kyoto 606-8501, Japan; ida@econ.kyoto-u.ac.jp

\section{Rei Goto} \\ Faculty of Economics, Konan University, Kobe 658-8501, Japan; reigoto@center.konan-u.ac.jp

\section{Yuko Takahashi} \\ Nara Women's University Health Service, Nara 630-8506, Japan; takahahi@cc.nara-wu.ac.jp \\ Shuzo Nishimura \\ Graduate School of Economics, Kyoto University, Kyoto 606-8501, Japan; shuzo@econ.kyoto-u.ac.jp
}

\begin{abstract}
This paper conducts a five-month follow-up survey of 608 Japanese adults who just started smoking cessation, and measures economic-psychological parameters such as the time preference rate and risk aversion coefficient using a conjoint analysis. We reach two main conclusions. First, cessation successes are more risk-averse than cessation failures, both at the starting and finishing points of the survey. Furthermore, between the two points, the time preference rates decrease for cessation successes, while the values increase for cessation failures. Second, we find that along with individual characteristics, economic-psychological parameters are important predictors of successful cessation. The time preference rate has a larger impact on cessation than the risk aversion coefficient.
\end{abstract}

Keywords smoking, cessation, time preference rate, risk aversion coefficient JEL classifications D81, D91, I12

${ }^{+}$Corresponding author: Takanori Ida, Graduate School of Economics, Kyoto University, Yoshida, Sakyo, Kyoto 606-8501, Japan; Tel. \& Fax: +81-75-753-3477; E-mail: ida@econ.kyoto-u.ac.jp 


\section{Introduction}

The economics of smoking attaches importance to the differences in individual characteristics, including age, gender, and nicotine dependency. Additional research has investigated the effects of economic-psychological parameters, including the time preference rate and risk aversion coefficient of habitual smoking ${ }^{1}$. What is still lacking, however, is economic-psychological research into successful smoking cessation. Since anti-smoking policies are being widely discussed in Japan and other countries, it is important to investigate the factors associated with successful cessation. This paper conducted a five-month follow-up survey of 608 Japanese adults who had just started smoking cessation, measured the time preference rate and risk aversion coefficient, and analyzed whether economic-psychological parameters can predict successful cessation.

Addiction is an important feature of smoking. The heavier one's nicotine dependency is, the more difficult smoking cessation is. Becker and Murphy (1988) proposed a rational addiction model in which people who heavily discounted future utilities were more likely to become addicted to smoking. Much research on time preference has reported that smokers are more impatient than nonsmokers and more frequently choose earlier-smaller rewards over later-larger rewards. Examples include Mitchell (1999), Bickel et al. (1999), Odum et al. (2002), Baker et al. (2003), Reynolds et al. (2003), and Ohmura et al. (2005). On the other hand, sufficient research on risk preference has not been accumulated to determine whether smoking and a risk-prone preference are associated $^{2}$. Thus, further research on the relationship between risk preference and smoking behavior is required. Another problem is that past studies measured the time preference rate and risk aversion coefficient separately when smoking was examined economic-psychologically ${ }^{3}$. Using a conjoint analysis, Ida and Goto (2008)

\footnotetext{
${ }^{1}$ The term behavioral economics is currently preferred to economic psychology; however, this paper uses the latter term because we emphasize the measurement of economic-psychological parameters.

${ }^{2}$ Mitchell (1999), Reynolds et al. (2003), and Ohmura et al. (2005) reported negligible correlations between them.

${ }^{3} \mathrm{~A}$ few studies have integrated the measurements of time and risk preferences, including Rachlin et al. (1991), Keren and Roelofsma (1995), Anderhub et al. (2001), and Yi et al.
} 
simultaneously measured the time preference rate and risk aversion coefficient at the individual level, and found that smokers were more impatient and risk-prone than nonsmokers. This paper follows Ida and Goto (2008) methodologically.

In the rational addiction models, it was implicitly assumed that economic-psychological parameters remain constant before and after smoking cessation. However, the success of cessation perhaps leads to a change in economic-psychological parameters, or conversely, successful cessation is caused by the change in the parameters. Recently, endogenous preferences have been introduced to explain smoking behavior. For example, Becker and Mulligan (1997) and Orphanides and Zervos (1998) suggested a variant of the rational addiction approach where the time preference rate was endogenously determined. We measured the time preference rate and the risk aversion coefficient both at the starting and finishing points (cessation failure or success for five months) of the survey. If the results of cessation are dependent on economic-psychological parameters or if these parameters change between the two points, these findings may support the endogenous preference models ${ }^{4}$.

The economics of smoking can be classified into research on smoking and that on quitting (Douglas 1998). This paper belongs to the latter category. Referring to the literature on quitting attempts, Jones (1994) treated the decision to quit smoking as a choice under uncertainty in an empirical model that incorporates health status, medical advice, addiction, and social interaction. Harris and Harris (1996) argued that people who benefitted the most from quitting wished to end their addictions the most. Hsieh (1998) showed that a change in health status as well as education had a positive effect on the probability of quitting. Hammar and Carlsson (2005) indicated that restricted availability, increased cigarette prices, cessation subsidies, and restrictions at restaurants, bars, and cafés all increased the expected probability of smoking cessation.

Furthermore, for successful cessation, Sander (1995) showed that educational background positively affected the odds of men and women over 25 years quitting smoking. Forster and Jones (2001) showed that the tax elasticity estimates of quitting were -0.60 for men and -0.46 for women. Keeler et al. (1993) indicated that successful (2006).

${ }^{4}$ Other studies regard smoking as time-inconsistent behavior (Lewit and Coate 1982, Baltagi and Levin 1986, Jones 1994, Gruber and Köszegi 2001, and Kan 2007). 
cessation could be explained by rational addiction models. Hyland et al. (2004) indicated that the most frequently cited reasons for predicting long-term cessation were health status, cost, and nicotine dependency. Hyland et al. (2006) discovered that cognitive variables, including the intention to quit, were associated with attempts to quit but not with successful cessation; on the other hand, behavioral variables related to task difficulty, including measures of dependence, predicted both making attempts and success.

Our main findings can be summarized as follows. We investigated the relation between successful cessation and economic-psychological parameters on the basis of a five-month follow-up survey intended for those who began quitting. As expected from the earlier literature, at the finishing point of the survey, cessation successes are more patient and risk-averse than failures. Interestingly, even at the starting point, successes are more risk-averse than failures, even though all respondents had just started quitting. These results show that economic-psychological parameters can predict successful cessation ex-ante and ex-post. Furthermore, we discovered that successes become more patient, while failures become more impatient between the two points. These results show that success or failure in a quitting attempt is associated with the endogenous formation of a preference. Second, we analyze successful cessation using a logit model by adding economic-psychological variables to frequently used sociodemographic and individual characteristic variables. As a result, the rate of time preference and the coefficient of risk aversion are important predictors for successful cessation along with the Fagerström Test for Nicotine Dependence (FTND) scores and the self-efficacy of quitting. The rate of time preference has a larger impact on successful cessation than on the coefficient of risk aversion. These findings provide rich information on who succeeds or fails, the type of support that is effective for quitting, and so on.

This paper is organized as follows. Section 2 explains the data sampling method and discusses the data characteristics. Section 3 introduces a conjoint analysis and proposes the discounted and expected utility models for estimating parameters. Section 4 presents the estimation results and investigates the relationship between successful cessation and economic-psychological parameters. Section 5 provides an economic model for explaining successful cessation. Finally, Section 6 provides concluding remarks. 


\section{Data sampling method}

In this section, we explain our data sampling method and the data characteristics. Data were gathered in May 2007 in the following two stages. At the first stage, we surveyed Japanese adults registered with a consumer monitoring investigative company that has about 85,900 monitors. We obtained 854 replies from individuals who had started quitting smoking within the last month. They were asked to reply to a questionnaire that included a conjoint analysis for measuring economic-psychological parameters and the FTND test for measuring nicotine dependency (Heatherton et al. 1991). (See APPENDIX I for the FTND test.) After excluding respondents who had smoked less than 100 cigarettes thus far and invalid respondents, we finally obtained 717 samples (response rate $=84.0 \%)^{5}$. At the second stage, we started a follow-up survey intended for these 717 samples. Excluding the nonresponses during the five-month follow-up, the final number of valid samples was 608 (follow-up rate $=$ 84.8\%). Among them, 287 people failed to quit smoking. We performed the same conjoint analysis for the failures when they reported that they had started smoking again. We also performed it for the 321 successes when the five-month follow-up period was completed. Table 1 summarizes the demographics of the sample data. Females account for $45.5 \%$ of the successes and $41.8 \%$ of the failures. The average ages are around 35 years for both the successes and failures. The FTND scores are 3.8 for the successes and 3.2 for the failures.

$<$ Table 1 $>$

Next, we looked at the continuation rate of smoking cessation. Although the figure dropped to $76 \%$ after one month, the rate of decline gradually decreased, and the figure converged to a little over $50 \%$. This result is consistent with earlier research (Hughes et al. 2004). Figure 1 indicates the durability of smoking cessation.

$<$ Figure 1 $>$

\footnotetext{
${ }^{5}$ The definition of a smoker here is somebody who has smoked at least 100 cigarettes thus far (U.S. Department of Health and Human Services 1991).
} 
Finally, we investigated the relationship between FTND scores and the durability of smoking cessation. Earlier research indicated that nicotine dependency was an important predictor for successful cessation. Our result is given in Figure 2. When nicotine dependency is measured by FTND scores, durability is higher for the upper middle (5-8 points) whose continuation rates are about $60-70 \%$, while it is lower for other scores (0-4 and 9-10 points) whose continuation rates are about 40-60\%. In short, nonlinearity was observed between the FTND scores and the durability of cessation. Although this conclusion reflects the definition of nicotine dependency, a similar relationship was observed in earlier literature (Hyland et al. 2006). Smokers with lower nicotine dependency may think that they can quit at any time, while those with the highest nicotine dependency are obviously physically and mentally addicted; therefore, they tend to fail to quit smoking.

$<$ Figure $2>$

\section{Conjoint analysis and estimation model}

In this section, we explain conjoint analysis, a stated preference method that we carried out on 608 valid respondents in order to simultaneously measure time and risk preferences. Conjoint analysis assumes that a service is a profile composed of attributes. If we include too many attributes and levels, respondents have difficulty answering the questions. On the other hand, if we include too few of them, the description of the alternatives becomes inadequate. After conducting several pretests, we determined the alternatives, attributes, and levels as follows:

\section{Alternative 1}

Reward, probability, and delay are fixed across profiles.

Reward: JP ¥100,000 (US \$909), Winning probability: 100\%, Time delay: None.

Alternative 2:

Reward, probability, and delay vary across profiles. 
Reward is either JP $¥ 150,000$ (US \$1,364), 200,000 (\$1,818), 250,000 (\$2,273), or $300,000(\$ 2,727)$.

The winning probability is $40,60,80$, or $90 \%$.

The time delay is 1 month, 6 months, 1 year, or 5 years.

Since the number of profiles becomes unwieldy if we consider all possible combinations, we avoided this problem by adopting an orthogonal planning method (see Louviere et al. 2000, Ch. 4 for details). Figure 3 depicts a representative questionnaire. We asked eight questions per respondent.

$<$ Figure $3>$

Next, we explain the discounted and expected utility models that form the basis for estimating the time preference rate and risk aversion coefficient. Let the utility of alternative $i$ be $V_{i}\left(\text { reward }_{i} \text {, probability }{ }_{i} \text {, timedelay }\right)_{i}$. The exponential discounted utility model and the (linear in probability) expected utility model are used for the functional form of $V_{i}^{6}$ :

Discounted utility: $\exp \left(-T I M E^{*}\right.$ timedelay $\left._{\mathrm{i}}\right){ }^{*}$ utility $\left(\operatorname{reward}_{\mathrm{i}}\right)$,

where parameter TIME denotes the rate of time preference.

Expected utility ${ }^{7}$ : probability $_{i}^{*}$ utility $\left(\right.$ reward $\left._{i}\right)$.

Accordingly, rewriting $V_{i}$, we obtain

$V_{i}\left(\right.$ reward $_{i}$, probability $_{i}$, timedelay $\left._{i}\right)$

$=\exp \left(- \text { TIME}^{*} \text { timedelay }_{\mathrm{i}}\right)^{*}$ probability $_{\mathrm{i}}^{*}$ utility $\left(\right.$ reward $\left._{\mathrm{i}}\right)$.

At this point, we simply specify the functional form of utility as the RISK-th power of reward. Such a utility function is called the constant relatively risk-averse form, where

\footnotetext{
${ }^{6}$ As is commonly known, the exponential discounted utility model was advocated by Samuelson (1937) and axiomatically defined by Koopmans (1960) and Fishburn and Rubinstein (1982). The expected utility model is attributed to Von Neumann and Morgenstern (1953).

${ }^{7}$ If we consider index $s$ as the state of nature, $s=1, \ldots, S$, the expected utility is written as $\Sigma_{s}=1, \ldots, s$ probability ${ }_{\mathrm{s}}{ }^{\mathrm{u}}$ utility $\left(\right.$ (reward $\left._{\mathrm{s}}\right)$. Note that we simply assume here that one alternative has only one state of nature other than the state of zero reward.
} 
the coefficient of the relative risk aversion is denoted by 1-RISK. Taking logarithms of both sides, we obtain

$\ln V_{i}\left(\right.$ reward $_{\mathrm{i}}$, probability $_{\mathrm{i}}$, timedelay $\left._{\mathrm{i}}\right)$

$=-$ TIME$^{*}$ timedelay $_{\mathrm{i}}+\ln$ probability $_{\mathrm{i}}+$ RISK$^{*} \ln \operatorname{reward}_{\mathrm{i}}$.

Two points should be noted here: first, a greater level of impatience implies a larger TIME; second, since a risk-averse attitude means $1-R I S K \in[0,1]$, a greater level of risk-aversion implies a larger 1-RISK.

One main objective of economic psychology is discovering and elucidating anomalies. The most famous anomaly in time preference is hyperbolic discounting, where the rate of time preference decreases with time delay (Frederick, Lowenstein, and O’Donoghue 2002). Two well-known anomalies in risk preference are certainty effect and loss aversion (Kahneman and Tversky 1979), which many models have struggled to account for. Nonetheless, this paper measures the rate of time preference and the coefficient of relative risk aversion based on the standard discounted and expected utility models, since some models explaining anomalies may be compatible with the standard model by a simple transformation of variables. For example, if psychological time is set as a logarithm of physical time, an exponential discounted model with respect to physical time can be transformed into a hyperbolic discounted model for psychological time (Takahashi 2005).

Last, we explain the estimation models. Conditional logit (CL) models, which assume independent and identical distribution (IID) of random terms, have been widely used in past studies. However, independence from the irrelevant alternatives (IIA) property derived from the IID assumption of the CL model is too strict to allow flexible substitution patterns. The most prominent scheme is a mixed logit (ML) model that accommodates differences in the variance of random components (or unobserved heterogeneity). These models are flexible enough to overcome the limitations of CL models by allowing random taste variation, unrestricted substitution patterns, and the correlation of random terms over time (McFadden and Train 2000). See APPENDIX II for the details of ML models.

In what follows, we assume that preference parameters regarding time and risk follow normal distribution:

TIME (rate of time preference)

RISK (coefficient of relative risk aversion represented by 1-RISK). 
Accordingly, we can demonstrate variety in the parameters at the individual level with the maximum simulated likelihood (MSL) method for estimation by setting 100 Halton draws ${ }^{8}$. Furthermore, since a respondent completes eight questions in the conjoint analysis, the data form a panel, and we can also apply a standard random effect estimation. We can calculate the estimator of the conditional mean of the random parameters.

\section{Estimation results and discussions}

In this section, the rate of time preference and the coefficient of relative risk aversion are measured simultaneously on the basis of the estimation results. The results are presented in Table 3. Having assumed that random parameters follow normal distribution, their means and standard deviations are reported. Furthermore, the estimation results are reported separately for smoking cessation successes and failures at the starting point, and for successes and failures at the finishing point. Both means and standard deviations are statistically significant for the time preference parameter TIME. All means are statistically significant for the risk preference parameter RISK, while standard deviations are not statistically significant for failures at the finishing point.

$<$ Table 3>

We measured the rate of time preference and the coefficient of risk aversion on the basis of the estimation results. These values are indicated in Table 4. A higher rate of time preference (TIME) implies greater impatience. On the other hand, the higher the coefficient of relative risk aversion (1-RISK), the more risk-averse is the result. Figure 4 displays the rate of time preference and Figure 5 displays the coefficient of risk aversion.

\footnotetext{
${ }^{8}$ Louviere et al. (2000, p. 201) suggest that 100 replications are normally sufficient for a typical problem involving five alternatives, 1,000 observations, and up to 10 attributes. The adoption of Halton sequence draw is an important problem to be examined (Halton 1960). Bhat (2001) found that 100 Halton sequence draws are more efficient than 1,000 random draws for simulating an ML model.
} 
Box diagrams report their $25 \%, 50 \%$, and $75 \%$ values. Figure 4 demonstrates that the rate of time preference is lower for successes than for failures at the finishing point. However, the values decrease for successes and increase for failures between the two points. Figure 5 shows that the coefficient of risk aversion is higher for successes than for failures, even at the starting point.

$<$ Table 4>

$<$ Figure $4>$

$<$ Figure 5 $>$

Previous literature has reported that smokers are more impatient than nonsmokers (Mitchell 1999, Bickel et al. 1999, Odum et al. 2002, Baker et al. 2003, Reynolds et al. 2004, Ohmura et al. 2005). These results are consistent with the rational addiction models because smoking satisfies present utilities but damages future utilities by increasing health risks. In addition, the previous findings that current smokers with higher nicotine dependency are more impatient and risk-prone and that ex-smokers are the most patient and risk-averse suggest that economic-psychological parameters are dependent on various smoking stages. These findings support the validity of habit formation or endogenous time-preference models ${ }^{9}$. At this point, we propose the following four hypotheses and statistically verify them using Welch's t-test. The results are indicated in Table 5.

$<$ Table 5>

Hypothesis 1: Preferences are different between smoking cessation successes and failures at the starting point.

Result 1: A statistically significant difference is not observed for the time preference rates, while successes are more risk-averse than failures for the risk aversion coefficients at the starting point.

\footnotetext{
${ }^{9}$ Uzawa (1968) proposed an endogenous time-preference model; Ryder and Heal (1973) proposed a habit formation model; and Shi and Epstein (1993) integrated these models.
} 
Hypothesis 2: Preferences vary for smoking cessation successes between the starting and finishing points.

Result 2: The time preference rates decrease, while a statistically significant difference is not observed for the risk aversion coefficients between the two points.

Hypothesis 3: Preferences vary for smoking cessation failures between the starting and finishing points.

Result 3: The time preference rates increase, while a statistically significant difference is not observed for the risk aversion coefficients between the two points.

Hypothesis 4: Preferences are different between smoking cessation successes and failures at the finishing point.

Result 4: Successes are more patient than failures for the time preference rates, while successes are more risk-averse than failures for the risk aversion coefficients at the finishing point.

Result 4 supports the previous finding that current smokers are more impatient and risk-prone than ex-smokers. Result 1 is interesting; smoking cessation successes and failures have different coefficients of risk aversion even when they start to quit. Result 2 suggests that preferences vary for successes between the starting and finishing points. We assume that ex-smokers almost escape from physically and mentally serious addiction after quitting for five months (Snyder et al. 1989). Thus, not smoking no longer causes irritability, and this change in smoking status may induce a preference to vary. Having pointed out that smoking increases the rate of time preference, we discovered that successful cessation decreases the rate of time preference. In other words, the endogenous formation of the rate of time preference is bidirectional between smoking and quitting. On the other hand, the endogenous formation of the coefficient of risk aversion is not verified in this research. Similarly, previous literature has not elucidated the relationship between smoking and risk aversion. Similar to Result 2, Result 3 shows the other possibility: preferences vary for failures between the starting and finishing points. The rate of time preference, not the coefficient of risk aversion, 
varies in Results 2 and 3.

Finally, a reservation must be mentioned. Since this research only investigated the relationship between smoking status and economic-psychological parameters, we cannot determine causality. A detailed study of causality lies beyond the scope of this paper. This is the most crucial area for future research ${ }^{10}$.

\section{Economic model of successful cessation}

In this section, we analyze effective predictors for successful cessation using a discrete choice model. Douglas (1998) surveyed the recent developments in smoking cessation research. Previous research that analyzed successful cessation using discrete choice models includes Lewit and Coate (1982), Chaloupka and Wechsler (1997), Harris and Chan (1999), Jones (1994), Sander (1995), Yen and Jones (1996), Hsieh (1998), and Dorsett (1999) ${ }^{11}$. Hyland et al. (2006) is also important because they categorized the explanatory variables for successful cessation into the following groups: sociodemographic variables (country, age, gender, education, income, etc.), beliefs about quitting (intention to quit smoking, self-efficacy of quitting, etc.), motivational variables (outcome expectancy of quitting, health worries, favorable attitudes toward smoking, etc.), past quitting history (number of attempts, longest break from smoking, etc.), and nicotine dependency.

On the basis of previous research, we define the following explanatory variables covering the categories suggested by Hyland et al. (2006):

- rate of time preference (at the starting and finishing points, and the difference between them)

- coefficient of risk aversion (at the starting and finishing points, and the difference

\footnotetext{
${ }^{10}$ Reynolds (2004) supported the hypothesis that a high rate of cigarette consumption is related to higher rates of time preference rather than the alternative hypothesis that argues that smokers are predisposed to higher rates of time preference.

${ }^{11}$ On the other hand, studies that have examined cessation using survival analysis include Douglas and Hariharan (1994), Douglas (1998), and Foster and Jones (2001).
} 
between them)

- age

- female dummy (0: male, 1 : female)

- FTND score $(0:$ FTND $=0-4$ or $9-10$ points, 1 : FTND $=5-8$ points)

- health status (1: excellent, ..., 5: terrible)

- mood status while not smoking (1: excellent, ..., 5: terrible)

- past quitting attempts (0: no, 1: yes)

- $\quad$ self-efficacy of quitting (1: certain failure, ..., 7: certain success)

- smoking cessation treatment method (0: no, 1: yes)

The newly added variables in this study include such economic-psychological variables as time preference rates and risk aversion coefficients. At this point, we classified them into values at the starting and finishing points, and the differences between them. Using a logit model, the explained variables are alternative 1 (success) and alternative 2 (failure). Table 6 indicates the estimation results. The rate of time preference and the coefficient of risk aversion at the starting point are used as explanatory variables in Model (a); the values at the finishing point, in Model (b); and their differences, in Model (c).

First, we examine the estimation results of the economic-psychological variables. In Models (a) and (b), the lower rate of time preference and the higher coefficient of risk aversion lead to a higher probability of successful cessation. Thus, economic-psychological variables are significantly associated with successful cessation. In Model (c), only the rate of time preference is statistically significant; the decrease in the rate of time preference after quitting is associated with the higher probability of successful cessation.

$<$ Table 6>

Next, we turn to the estimation results of other variables. FTND scores of 5-8 have positive effects on successful cessation in all models. A good mood status while not smoking is only associated with successful cessation in Model (c). Past quitting attempts negatively influence successful cessation in Models (a) and (c). The higher self-efficacy of quitting is associated with successful cessation in all models. A smoking 
cessation treatment method only positively impacts successful cessation in Model (a). On the other hand, age, gender, and health status are not associated with successful cessation.

Last, we analyze the elasticities of the probability of successful cessation with respect to the rate of time preference and the coefficient of risk aversion. Table 7 indicates the values. We can summarize the main points as follows.

- The elasticity of the success rate with respect to the rate of time preference is -0.743 at the starting point and -1.678 at the finishing point. The rate of time preference at the finishing point has a larger impact on the success rate as compared to that at the starting point.

- The elasticity of the success rate with respect to the coefficient of risk aversion is 0.434 at the starting point and 0.241 at the finishing point. The coefficient of risk aversion at the starting point has a larger impact on the success rate as compared to that at the finishing point.

- On comparing the elasticity values, we find that the rate of time preference has a larger impact on the success rate than the coefficient of risk aversion.

$<$ Table $7>$

In sum, we demonstrated that economic-psychological parameters such as time preference rate and risk aversion coefficient are significantly associated with successful cessation of smoking.

\section{Conclusion}

This paper conducted a five-month follow-up survey of 608 Japanese adults who had just started smoking cessation. Of the respondents, $52 \%$ succeeded while the remaining $48 \%$ failed to quit smoking. Focusing on economic-psychological parameters such as time preference rate and risk aversion coefficient, this paper investigated the differences in preferences between successes and failures. Consequently, we found statistically significant differences in the coefficient of risk aversion for successes and failures at the 
starting point. We also discovered statistically significant differences in both their rate of time preference and the coefficient of risk aversion at the finishing point. Furthermore, the rate of time preference changed between the two points for both successes and failures. These conclusions suggest not only that economic-psychological parameters are associated with successful cessation but also that these parameters may be endogenously formed depending on smoking status. This paper also analyzed successful cessation using a logit model. Besides the upper-middle FTND scores and the self-efficacy of quitting, the rate of time preference and the coefficient of risk aversion are critical predictors for successful cessation.

Finally, the following problems remain unsolved. First, we did not consider how the decision to quit smoking is causally related to differences in preferences. A detailed investigation of causality is required. Second, we only dealt with smoking cessation; however, in the future, analyzing addictive behaviors such as drinking, gambling, and substance abuse might also be interesting. Third, we must develop better analysis methods. For example, applying survival analysis to our data might be beneficial. These are potential topics for future research. 


\section{APPENDIX I FTND test}

FTND is composed of the following six questions (Heatherton et al. 1991):

1. How soon after you wake up do you smoke your first cigarette? (1) Within 5 minutes (3 points), (2) 6-30 minutes ( 2 points), (3) 31-60 minutes (1 point), (4) After 60 minutes ( 0 points $)$

2. Do you find it difficult to refrain from smoking in places where it is forbidden, e.g., in church, at the library, in a cinema, etc.? (1) Yes (1 point), (2) No (0 points)

3. Which cigarette would you hate to give up the most? (1) The first one in the morning (1 point), (2) All others (0 points)

4. How many cigarettes do you smoke in a day? (1) 10 or less (0 points), (2) 11-20 (1 point), (3) 21-30 (2 points), (4) 31 or more (3 points)

5. Do you smoke more frequently during the first hours after waking up than you do during the rest of the day? (1) Yes (1 point), (2) No (0 points)

6. Do you smoke even if you are so ill that you have to remain in bed for most of the day? (1) Yes (1 point), (2) No (0 points) 


\section{APPENDIX II ML model}

Assuming that parameter $\beta_{n}$ is distributed with density function $f\left(\beta_{n}\right)$ (Train 2003, Louviere et al. 2000), the ML specification allows for repeated choices by each sampled decision maker in such a way that the coefficients vary over people but are constant over choice situations for each person. The logit probability of decision maker $n$ choosing alternative $i$ in choice situation $t$ is expressed as

$$
L_{n i t}\left(\beta_{n}\right)=\prod_{t=1}^{T}\left[\exp \left(V_{n i t}\left(\beta_{n}\right)\right) / \sum_{j=1}^{J} \exp \left(V_{n j t}\left(\beta_{n}\right)\right)\right]
$$

which is the product of normal logit formulas, given parameter $\beta_{n}$, the observable portion of utility function $V_{\text {nit }}$, and alternatives $j=1, \ldots, J$ in choice situations $t=1, \ldots, T$. Therefore, ML choice probability is a weighted average of logit probability $L_{n i t}\left(\beta_{n}\right)$ evaluated at parameter $\beta_{n}$ with density function $f\left(\beta_{n}\right)$, which can be written as

$$
P_{n i t}=\int L_{n i t}\left(\beta_{n}\right) f\left(\beta_{n}\right) d \beta_{n} .
$$

In the linear-in-parameter form, the utility function can be written as

$$
U_{n i t}=\gamma^{\prime} x_{n i t}+\beta_{n}{ }^{\prime} z_{n i t}+\varepsilon_{n i t},
$$

where $x_{\text {nit }}$ and $z_{\text {nit }}$ denote observable variables, $\gamma$ denotes a fixed parameter vector, $\beta_{n}$ denotes a random parameter vector, and $\varepsilon_{n i t}$ denotes an independently and identically distributed extreme value (IIDEV) term.

Since ML choice probability is not expressed in closed form, simulations need to be performed for the ML model estimation (see Train 2003, p. 148 for details). We can also calculate the estimator of the conditional mean of the random parameters, conditioned on individual specific choice profile $y_{n}$, given as

$$
h\left(\beta \mid y_{n}\right)=\left[P\left(y_{n} \mid \beta\right) f(\beta)\right] / \int P\left(y_{n} \mid \beta\right) f(\beta) d \beta .
$$

Here, we assume that preference parameters regarding time and risk follow normal distribution:

TIME (rate of time preference)

RISK (coefficient of relative risk aversion represented by 1-RISK).

The random utility that person $n$ obtains from choosing alternative $i$ in choice situation $t$ can be written as follows: 


$$
U_{n i t}=-\alpha * \text { TIME }^{*} \text { timedelay }_{\text {nit }}+\alpha * \ln \text { probability }_{\text {nit }}+\alpha * \text { RISK }^{*} \ln \text { reward }_{n i t}+\varepsilon_{\text {nit }} \text {, }
$$

where $\alpha$ is a scale parameter that is not separately identified from free parameters and is normalized to one (Hensher, Rose, and Green 2005, p. 536) ${ }^{12}$.

${ }^{12}$ Louviere, Hensher, and Swait (2000, pp. 142-143) showed that variance is an inverse function of the scale, $\sigma^{2}=\pi^{2} / 6 \alpha^{2}$. Therefore, associated variance $\sigma^{2}$ becomes 1.645 . 


\section{References}

Akkaya, A., Ozturk, O., Cobanoglu, H., Bircan, H.A., Simsek, S., and Sahin, U., 2006. Evaluation of patients followed up in a cigarette cessation clinic. Respirology 11, 311-316.

Anderhub, V., Guth, W., Gneezy, U., and Sonsino, D., 2001. On the interaction of risk and time preferences: An experimental study. German Economic Review 2, 239-253.

Baker, F., Johnson, M.W., and Bickel, W.K., 2003. Delay discounting in current and never-before cigarette smokers: Similarities and differences across commodity, sign, and magnitude. Journal of Abnormal Psychology 112, 382-92.

Baltagi, B.H. and Levin, D., 1986. Estimating dynamic demand for cigarettes using panel data: The effects of bootlegging, taxation, and advertising reconsidered. Review of Economics and Statistics 68, 148-155.

Becker, G.S. and Murphy, K.M., 1988, A theory of rational addiction. Journal of Political Economy 96, 675-700.

Becker, G. and Mulligan, C., 1997. The endogenous determination of time preference. Quarterly Journal of Economics 112, 729-758.

Bhat, C., 2001. Quasi-random maximum simulated likelihood estimation of the mixed multinomial logit model. Transportation Research B 35, 677-693.

Bickel, W.K., Odum, A.L., and Madden, G.J., 1999. Impulsivity and cigarette smoking: Delaty discounting in current never, and ex-smokers. Psychopharmacology 146: 447-454.

Chaloupka, F.J. and Wechsler, H., 1997. Price, tobacco control policies and smoking among young adults. Journal of Health Economics 16, 359-373.

Dorsett, R. 1999. An econometric analysis of smoking prevalence among lone mothers. Journal of Health Economics 18, 429-441.

Douglas, S. and Hariharan, G., 1994. The hazard of starting smoking: Estimates from a split population duration model. Journal of Health Economics 13, 213-230.

Douglas, S., 1998. The duration of the smoking habit. Economics Inquiry 36, 49-64.

Fishburn, P.C. and Rubinstein, A., 1982. Time preference, International Economic Review 23, 677-94.

Frederick, S., Lowenstein, G., and O'Donoghue, T., 2002. Time discounting and time 
preference: A critical review. Journal of Economic Literature 40, 351-401.

Forster, M. and Jones, A.M., 2001. The role of tobacco taxes in starting and quitting smoking: Duration analysis of British data. Journal of the Royal Statistical Society $164,517-547$.

Gruber, J. and Köszegi, B., 2001. Is addiction 'rational?' Theory and evidence. Quarterly Journal of Economics 116, 1261-1303.

Halton, J., 1960. On the efficiency of evaluating certain quasi-random sequences of points in evaluating multi-dimensional integrals. Numerische Mathematik 2, 84-90.

Hammar, H. and Carlsson, F., 2005. Smokers' expectations to quit smoking. Health Economics 14, 257-267.

Harris, W.T. and Harris, L., 1996. The decision to quit smoking: Theory and evidence. Journal of Social Economics 25, 601-618.

Harris, J.E. and Chan, S.W., 1999. The continuum of addiction: Cigarette smoking in relation to price among Americans 15-29. Health Economics 8, 81-86.

Heatherton, T.F., Kozlowski, L.T., Frecker, R.C., and Fagerström, K.O., 1991. The Fagerström test for nicotine dependence: A revision of the Fagerström tolerance questionnaire. British Journal of Addiction 86, 1119-1127.

Hensher, D.A., Rose, J.M., and Greene, W.H., 2005. Applied Choice Analysis. Cambridge University Press.

Hsieh, C.R., 1998. Health risk and the decision to quit smoking. Applied Economics 30, 795-804.

Hyland, A., Qiang L., Bauer, J.E., Giovino, G.A., Steger, C., and Cummings, K.M. 2004. Predictors of cessation in a cohort of current and former smokers followed over 13 years. Nicotine \& Tobacco Research 3, 363-369.

Hyland, A., Borland, R., Li1, Q., Yong, H.H., McNeill, A., Fong, G.T., O’Connor, R.J., and Cummings, K.M. 2008. Individual-level predictors of cessation behaviours among participants in the International Tobacco Control (ITC) Four Country Survey. Tobacco Control 15, 83-94.

Hughes, J.R., Keely, J., and Naud S. 2004. Shape of the relapse curve and long-term abstinence among untreated smokers. Addiction 99, 29-38.

Ida, T. and Goto, R., 2008. Simultaneous measurement of time and risk preferences: Stated preference discrete choice modeling analysis depending on smoking 
behavior. International Economic Review, forthcoming.

Jones, A.M., 1994, Health, addiction, social interaction and the decision to quit smoking, Journal of Health Economics 13, 93-110.

Kahneman, D. and Tversky, A., 1979. Prospect theory: An analysis of decision under risk. Econometrica 47, 263-291.

Kan, K., 2007, Cigarette smoking and self-control, Journal of Health Economics 26, 61-81.

Keeler, T.E., Hu, T.W., Barnett, P.G., and Manning, W.G., 1993. Taxation, regulation and addiction: A demand function for cigarettes based on time-series evidence. Journal of Health Economics 12, 1-18.

Keren, G. and Roelofsma, P., 1995. Immediacy and certainty in intertemporal choice. Organizational Behavior and Human Decision Processes 63, 287-297.

Koopmans, T.C., 1960. Stationary ordinal utility and impatience. Econometrica 28, 287-309.

Lewit, E.M., Coate, D., 1982. The potential for using excise taxes to reduce smoking. Journal of Health Economics 3, 121-145.

Louviere, J.J., Hensher, D.A., and Swait, J.D., 2000. Stated Choice Methods, Cambridge University Press.

McFadden, D. and Train, K.E., 2000. Mixed MNL models of discrete choice models of discrete response. Journal of Applied Econometrics 15, 447-470.

Mitchell, S.H., 1999. Measures of impulsivity in cigarette smokers and non-smokers. Psychopharmacology 146, 455-464.

Odum, A.L., Madden, G.J., and Bickel, W.K., 2002. Discounting of delayed health gains and losses by current, never- and ex-smokers of cigarettes. Nicotine and Tobacco Research 4, 295-303.

Ohmura, Y., Takahashi, T., and Kitamura, N., 2005. Discounting delayed and probabilistic monetary gains and losses by smokers of cigarettes. Psychopharmacology 182, 508-515.

Orphanides, A. and Zervos, D., 1998. Myopia and addictive behavior. Economic Journal $108,75-92$.

Rachlin, H., Raineri, A., and Cross, D., 1991. Subjective probability and delay. Journal of Experimental Analysis of Behavior 55, 233-44.

Reynolds, B., Karraker, K., Horn, K., and Richards, J.B., 2003. Delay and probability 
discounting as related to different stages of adolescent smoking and non-smoking. Behavioural Processes 64, 333-344.

Reynolds, B., 2004. Do high rates of cigarette consumption increase delay discounting? A cross-sectional comparison of adolescent smokers and young-adult smokers and nonsmokers. Behavioural Processes 67, 545-549.

Reynolds, B., Richards, J.B., Horn, K., and Karraker, K., 2004. Delay discounting and probability discounting as related to cigarette smoking status in adults. Behavioural Processes 65, 35-42.

Ryder, H.E. and Heal, G.M. 1973. Optimum growth with intertemporally dependent preferences. Review of Economic Studies 40, 1-33.

Samuelson, P., 1937. A note on measurement of utility, Review of Economic Studies 4, $155-61$.

Sander, W., 1995. Schooling and quitting smoking. Review of Economics and Statistics $129,191-198$.

Shi, S. and Epstein, L.G., 1993. Habits and time preference. International Economic Review 34, 61-84.

Snyder, F.R., Davis, F.C., Henningsfield, J.E., 1989. The tobacco withdrawal syndrome: Performance decrements assessed on a computerized test battery. Drug Alcohol Depend 23, 259-266.

Takahashi, T., 2005. Loss of self-control in intertemporal choice may be attributable to logarithmic time-perception. Medical Hypotheses 65, 691-693.

Train, K.E., 2003. Discrete Choice Methods with Simulation, Cambridge University Press.

U.S. Department of Health and Human Services 1991. Smoking Data Guide. Bibliographies and Data Sources. Hyattsville, Maryland.

Uzawa, H., 1968. Time preference, the consumption function, and optimum asset holdings. in Wolfe, J.N. (ed.) Capital and Growth: Papers in Honour of Sir John Hicks. Chicago: Aldine.

Von Neumann, J. and Morgenstern, O., 1953. Theory of Games and Economic Behaviour. Princeton University Press.

Yen, S. and Jones, A.M., 1996. Individual cigarette consumption and addiction: A flexible limited dependence variable approach. Health Economics 5, 105-117.

Yi, R., de la Piedad, X., and Bickel, W.K., 2006. The combined effects of delay and 
probability in discounting. Behavoural Processes 73, 149-155. 
Table 1: Data demographics

At the 1st stage (screening)

No. of samples

Female ratio Average age Smokers ratio

85,900

$53.7 \%$

38.2

$23.3 \%$

No. of cigarettes smoked in lifetime

from 1 to 100 more than 100

$40.1 \% \quad 20.7 \% \quad 39.3 \%$

At the 2nd stage (follow-up)

\begin{tabular}{ccccc} 
& No. of sample & Female ratio & Average age & FTND score \\
\cline { 2 - 5 } Cessation successes & 321 & $45.5 \%$ & 35.0 & 3.8 \\
Cessation failures & 287 & $41.8 \%$ & 35.1 & 3.2 \\
\hline Total & 608 & $43.8 \%$ & 35.0 & 3.5 \\
\hline
\end{tabular}


Figure 1: Durability of smoking cessation

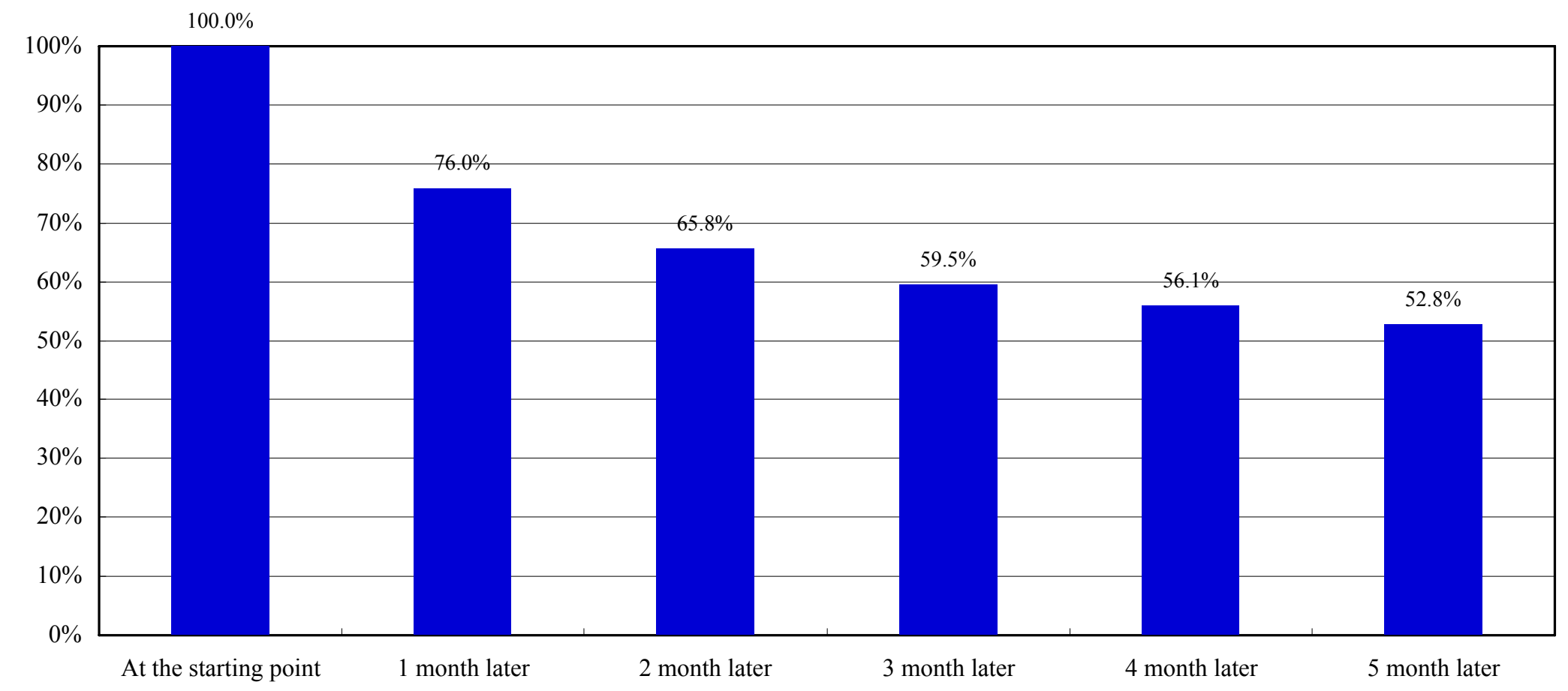


Figure 2: Continuing rate of cessation depending on FTND score

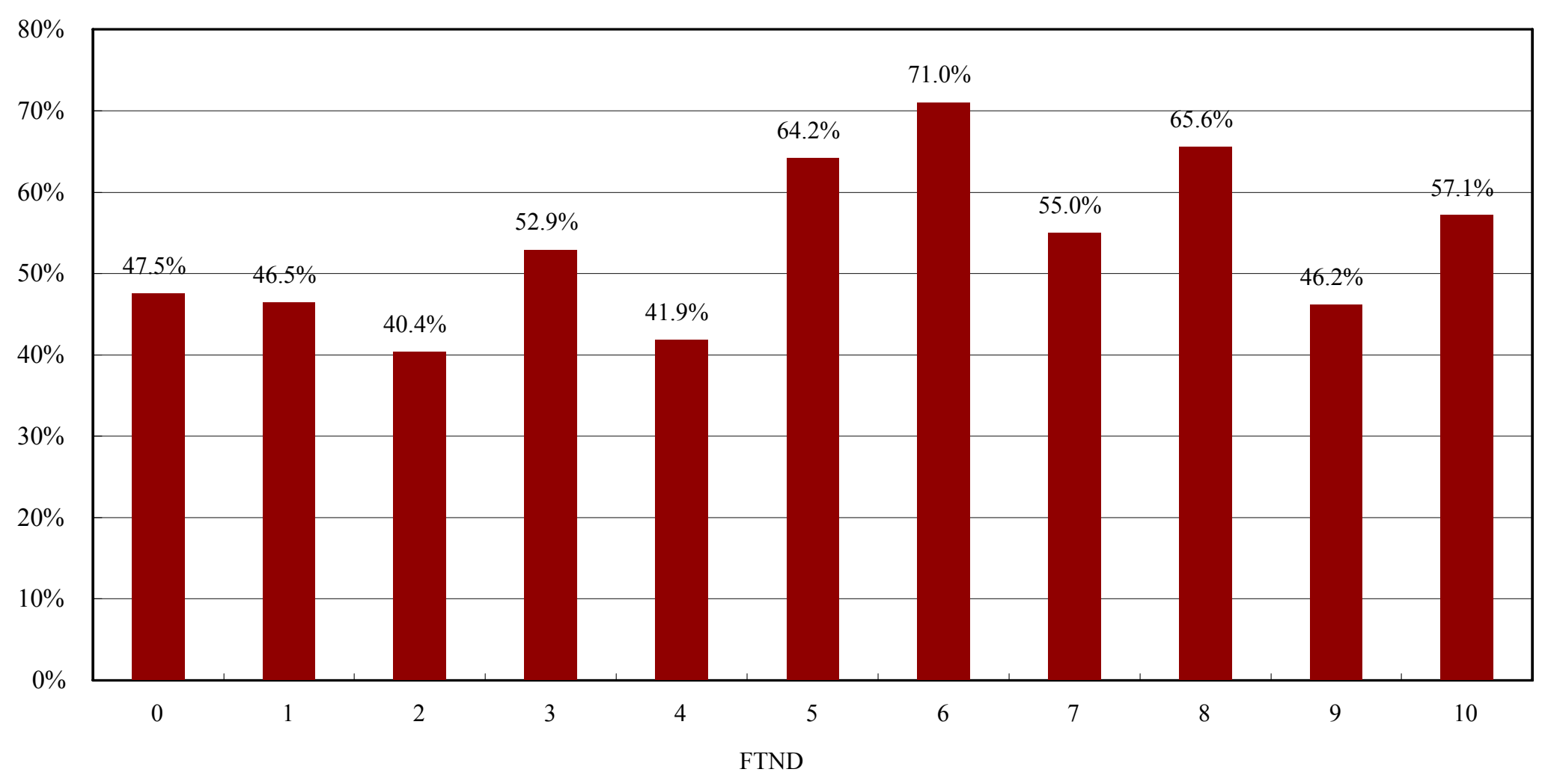


Figure 1: Representative questionnaire

\begin{tabular}{|c|c|c|}
\hline & ALTERNATIVE 1 & ALTERNATIVE 2 \\
\hline REWARD & JPY 100,000 & JPY 250,000 \\
\hline TIME DELAY & NOW & 1 MONTH LATER \\
\hline \multirow[t]{2}{*}{ WINNING PROBABILITY } & $100 \%$ & $80 \%$ \\
\hline & $\downarrow$ & $\downarrow$ \\
\hline CHOOSE ONE & & \\
\hline
\end{tabular}


Table 3: Estimation results (i)

Successes at the starting point Successes at the finishing point Failures at the starting point Failures at the finishing point

\begin{tabular}{|c|c|c|c|c|c|c|c|c|}
\hline No. of Samples & $321 * 8$ & & $297 * 8$ & & $287 * 8$ & & $245 * 8$ & \\
\hline Maximum LL & -1360.7 & & -1271.0 & & -1196.7 & & -1005.0 & \\
\hline Initial LL & -1780.0 & & -1646.9 & & -1591.5 & & -1358.6 & \\
\hline Pseudo R2 & 0.236 & & 0.228 & & 0.248 & & 0.260 & \\
\hline \multirow{3}{*}{ TIME (MEAN) } & Coeff./S.E. & & Coeff./S.E. & & Coeff./S.E. & & Coeff./S.E. & \\
\hline & 0.0673 & \multirow{2}{*}{$* * *$} & 0.0544 & \multirow{2}{*}{$* * *$} & 0.0685 & \multirow{2}{*}{$* * *$} & 0.0804 & **** \\
\hline & 0.0083 & & 0.0075 & & 0.0081 & & 0.0098 & \\
\hline \multirow{2}{*}{ RISK (MEAN) } & 0.6825 & \multirow{2}{*}{$* * *$} & 0.7210 & \multirow{2}{*}{$* * *$} & 0.8689 & \multirow{2}{*}{$* * *$} & 0.9074 & \\
\hline & 0.0813 & & 0.0886 & & 0.0901 & & 0.0926 & \\
\hline \multirow{2}{*}{ TIME (S.D.) } & 0.0429 & \multirow{2}{*}{$* * *$} & 0.0332 & \multirow{2}{*}{$* * *$} & 0.0381 & \multirow{2}{*}{$* * *$} & 0.0503 & $* * *$ \\
\hline & 0.0073 & & 0.0078 & & 0.0071 & & 0.0081 & . \\
\hline \multirow{2}{*}{ RISK (S.D.) } & 0.3173 & \multirow{2}{*}{ * } & 0.5883 & \multirow{2}{*}{$* * *$} & 0.5519 & \multirow{2}{*}{$* * *$} & 0.2023 & \\
\hline & 0.1877 & & 0.1314 & & 0.1343 & & 0.3029 & \\
\hline
\end{tabular}

Note: Coefficients in the upper row, standard errors (S.E.) in the lower row,

*** at the $1 \%$ significance level, ** at the $5 \%$ significance level, *at the $10 \%$ significance level. 
Table 4: The rate of time preference and the coefficient of risk aversion

\begin{tabular}{cccc}
\hline \multicolumn{1}{c}{ At the starting point } & & Successes & Failures \\
\hline \multirow{2}{*}{ The rate of time preference } & Mean & $0.0673 * * *$ & $0.0685 * * *$ \\
& S.D. & $0.0429 * * *$ & $0.0381 * * *$ \\
\hline The coefficient of risk aversion & Mean & $0.3175 * * *$ & $0.1311 * * *$ \\
\hline At the finishing point & S.D. & $0.3173 *$ & $0.5519 * * *$ \\
\hline The rate of time preference & & & \\
\hline The coefficient of risk aversion & Mean & $0.0544 * * *$ & $0.0804 * * *$ \\
\hline & S.D. & $0.0332 * * *$ & $0.0503 * * *$ \\
\hline
\end{tabular}


Figure 4: The rate of time preference

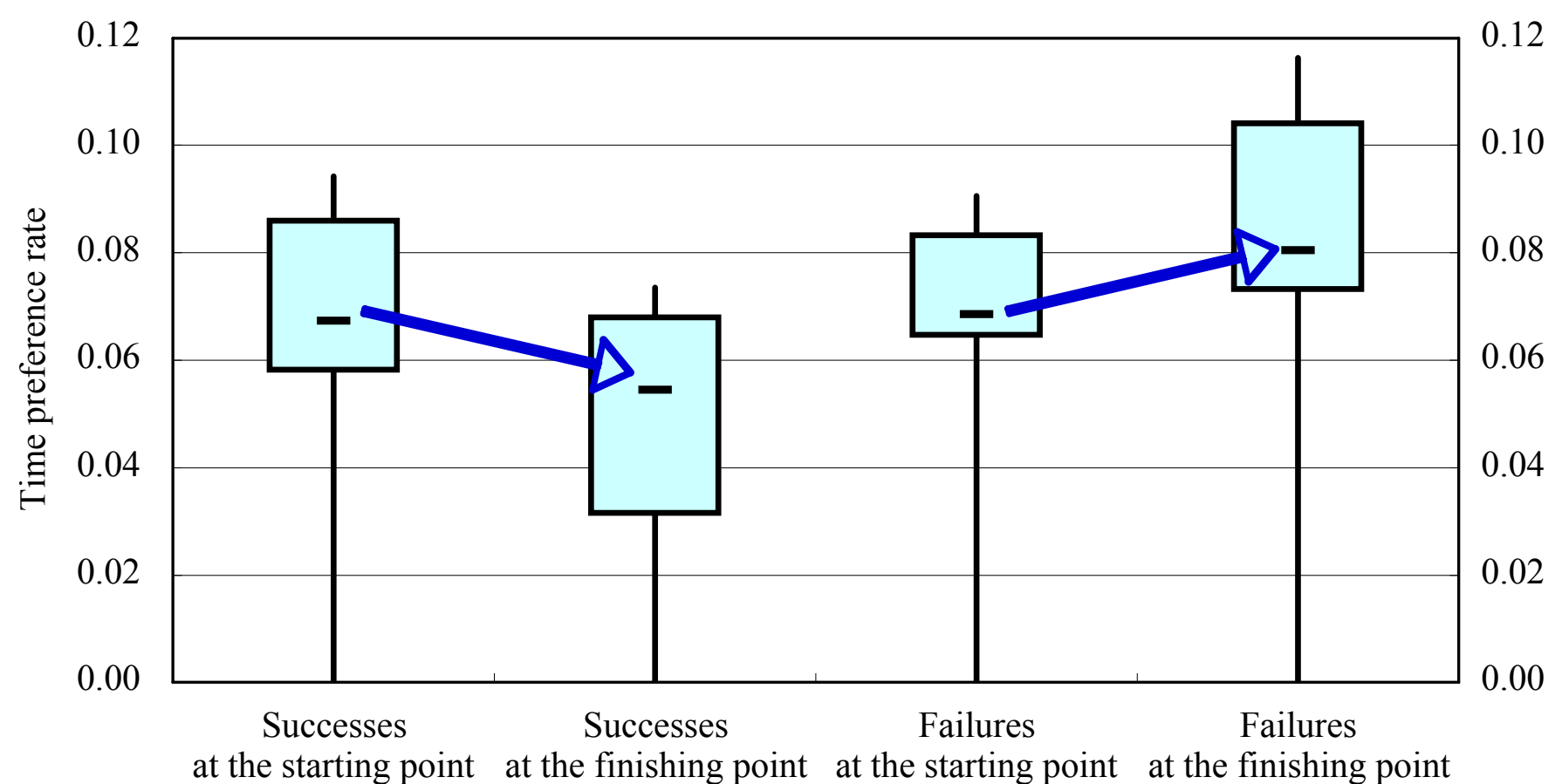


Figure 5: The coefficient of risk aversion

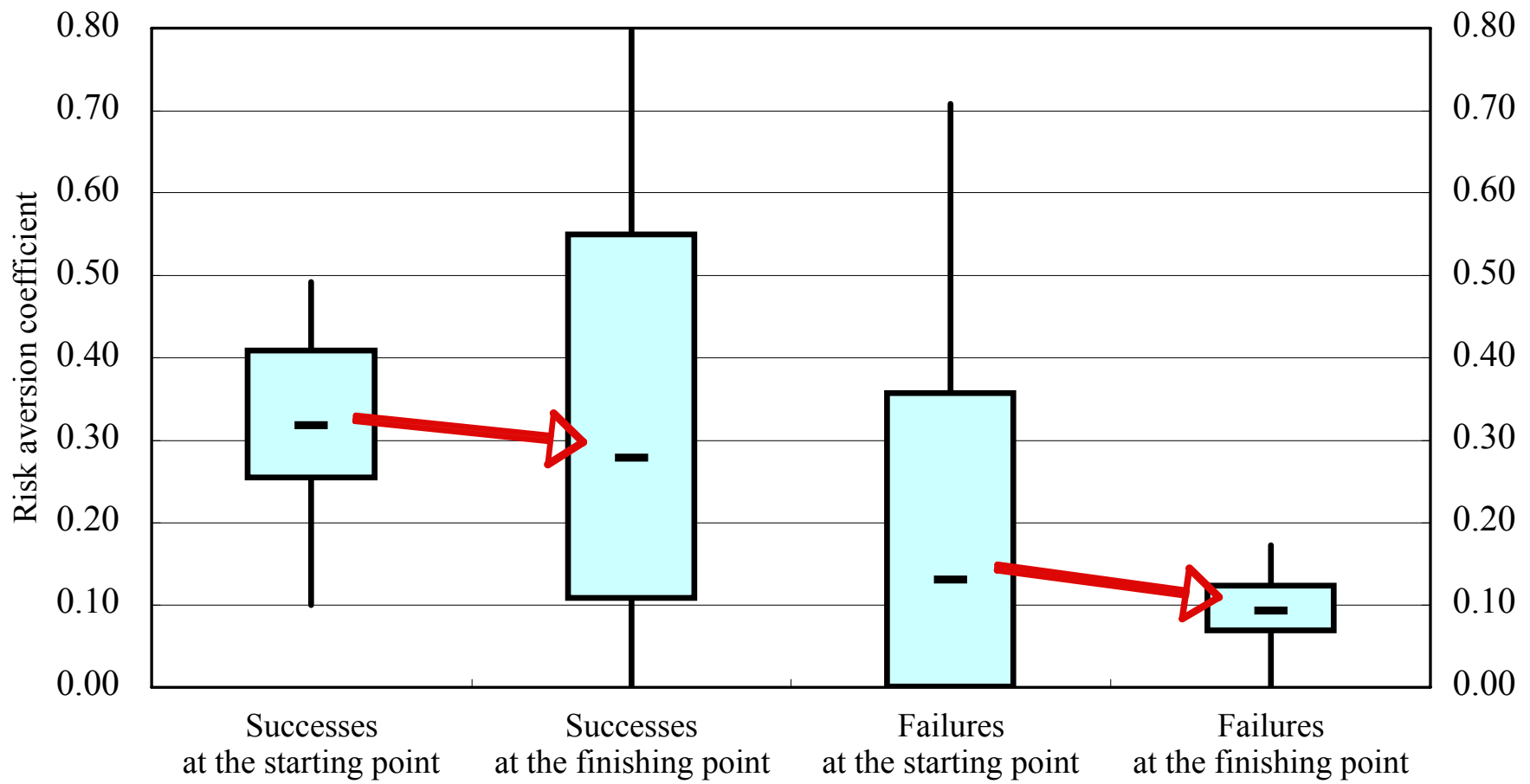


Table 5: Welch-t test

The rate of time preference The coefficient of risk aversion

\begin{tabular}{cccc} 
Successes at the starting point & Welch t value & 0.381 & 5.029 \\
\cline { 3 - 4 } vs. Failures at the starting point & $\mathrm{p}$ value & 0.703 & 0.000 \\
\hline Successes at the starting point & Welch t value & 4.171 & 1.003 \\
vs. Successes at the finishing point & $\mathrm{p}$ value & 0.000 & 0.316 \\
\hline Failures at the starting point & Welch t value & 3.032 & 1.098 \\
vs. Failures at the finishing point & $\mathrm{p}$ value & 0.003 & 0.273 \\
\hline Successes at the finishing point & Welch t value & 6.925 & 5.106 \\
vs. Failures at the finishing point & $\mathrm{p}$ value & 0.000 & 0.000 \\
\hline
\end{tabular}


Table 6: Estimation results (ii)

\begin{tabular}{|c|c|c|c|c|c|c|c|c|c|}
\hline & \multicolumn{3}{|c|}{ (a) At the starting point } & \multicolumn{3}{|c|}{ (b) At the finishing point } & \multicolumn{3}{|c|}{ (c) Between the two periods } \\
\hline & No. of Sample & 608 & & No. of Sample & 542 & & No. of Sample & 514 & \\
\hline & Max LL & -318.9 & & Max LL & -236.4 & & Max LL & -286.2 & \\
\hline & Initial LL & -421.4 & & Initial LL & -375.7 & & Initial LL & -356.3 & \\
\hline & McFadden R2 & 0.243 & & McFadden R2 & 0.371 & & McFadden R2 & 0.197 & \\
\hline & Estimates & S.E. & & Estimates & S.E. & & Estimates & S.E. & \\
\hline Constant & 0.4915 & 0.9596 & & 2.5535 & 1.1717 & & 1.2612 & 0.9839 & \\
\hline Time preference & -21.7851 & 4.6772 & $* * *$ & -45.8737 & 4.5022 & $* * *$ & -32.3802 & 3.9136 & $* * *$ \\
\hline Risk aversion & 6.4931 & 0.6605 & $* * *$ & 5.6873 & 0.6608 & $* * *$ & -0.0451 & 0.4298 & \\
\hline Age & -0.0003 & 0.0101 & & -0.0095 & 0.0124 & & -0.0119 & 0.0107 & \\
\hline Female dummy & -0.0275 & 0.2038 & & -0.3423 & 0.2506 & & -0.0158 & 0.2176 & \\
\hline FTND 5-8 score & 0.5225 & 0.2150 & $* *$ & 0.4998 & 0.2661 & * & 0.6448 & 0.2288 & $* * *$ \\
\hline Health status & -0.1401 & 0.1179 & & -0.0660 & 0.1396 & & -0.0822 & 0.1219 & \\
\hline Mood status while not smoking & -0.2150 & 0.1358 & & -0.1890 & 0.1631 & & -0.4329 & 0.1404 & $* * *$ \\
\hline Past quitting attempt & -0.6720 & 0.2683 & $* *$ & -0.5524 & 0.3015 & & -0.6152 & 0.2847 & $* *$ \\
\hline Self-efficacy of quitting & 0.1659 & 0.0778 & $* *$ & 0.2980 & 0.0968 & $* * *$ & 0.2160 & 0.0827 & $* * *$ \\
\hline Smoking cessation treatment & 0.7369 & 0.2744 & $* * *$ & 0.1840 & 0.3290 & & 0.4520 & 0.2804 & \\
\hline
\end{tabular}

Note: $* * * 1 \%$ significance level, $* * 5 \%$ significance level, $* 10 \%$ significance level 
Table 7: Elasticities

$\begin{array}{lll}\text { (a) At the starting point } & \text { (b) At the finishing point } & \text { (c) Between the two periods }\end{array}$

\begin{tabular}{ccccccc} 
& TIME & RISK & TIME & RISK & TIME & RISK \\
\cline { 2 - 7 } Successful cessation & -0.743 & 0.434 & -1.678 & 0.241 & -0.187 & -0.001 \\
Unsuccessful cessation & 0.814 & -1.128 & 1.368 & -0.842 & 0.199 & 0.002 \\
\hline
\end{tabular}

